\title{
Knowledge, Attitude and Practice of dental treatment among medical officers at PHC's of Amer and Jamwaramgarh Tehsil, Jaipur, Rajasthan - A Pilot Study
}

\author{
Dr. Anup.N ${ }^{1}$; Dr. Gautam Biswas ${ }^{2}$; Dr. Shravani G. ${ }^{3}$; Dr. PriyankaSontakke ${ }^{4}$; \\ Dr. Himanshu Kumawat ${ }^{5}$; Dr. Prateek Jain ${ }^{6}$ \\ 1.Professor and Head, 2.,3.Senior lecturer, 4.,5.,6., Post graduate student
}

\begin{abstract}
:
Aim:To assess the awareness among medical officers about dental and medical facilities available in the Primary Health Center of Amer and Jamwaramgarh tehsil, Jaipur, India.

Objective:

1. To determine the extent of dental health knowledge among medical officers in PHC.

2. To assess the dental awareness and attitudes of medical officers.

3. To assess the medical awareness and attitudes of medical officers.

4. To compare the awareness of masters and graduates regarding their dental and medical practice awareness in PHC.
\end{abstract}

Materials and Method: A total of 36 doctors at different PHCs of Amer and Jamwaramgarh Jaipur were asked to participate, all were agreed to participate and following proper inclusion \& exclusion criteria were taken into the study. A structured questionnaire(Cronbach a 0.80) was used to assess the knowledge, attitude and practices towards dental and medical facilities available in the Primary Health Center of Amer and Jamwaramgarh , Jaipur.

Results: Amongst the participants 13 were females and 23 were males. The mean age of 34.08 years.The duration of professional life of the medical participants ranged from 1-30 years with mean of $8.39 .25 \%$ provide the dental treatment, no dental clinic separately found at PHCs.

Conclusion: Medical officers at PHCs showed limited knowledgeregarding dental problems. Oral health is neglected inrural areas so there is need for at least one dentist inthe PHCs to promote the oral health of the people

Keywords: Medical officers, dentist, primary health centre

\section{Introduction}

Oral health has always been an intimate part of general health and affects the total wellbeing of individuals. Oral cavity is associated with the development of healthy personality, perceptions and overall experience of pleasure. Virtous oral health is preserved by proper dealings which people learn and run through regularly. The oral cavity is an integral part of the body and there are many systemic diseases which has oral manifestations that are to be accomplished in both healthy and medically compromised people.

The Indian government has sworned to deliver Universal Health coverage with the primary health care concept.The strategy, Health For All is engrossed mostly on medical problems but in many countries they have protracted these PHC principles to embrace dental service too.

In developing countries, the teaching of PHC workers should discourse the special needs of the communities. Their exercise should also be based on patterns of oral disease, prevalence of population in a particular area.

Generally, PHC is considered mainly for Medical visit and not a dental visit. It is also found that,concerning the dental knowledge of medical practitioners, very few studies have collected data and hence there is a need to include dental services in PHC principles in India. Therefore, this study was conducted to assess the knowledge, attitude and practice of dental treatment among medical officer's at PHC's of Amer and Jamwaramgarh tehsil, Jaipur, Rajasthan.

\section{Methodology}

A pilot study was done at different PHCs of Amer and Jamwaramgarh tehsils of Jaipur City in the month of august and September 2014. A total of 36 participants (27 Masters and 9 MBBS) were surveyed. Ethical clearance was taken from an institutional review board of MaharajVinayak Global University, Jaipur. 
Also the informed consent was taken from medical officers. They were approached personally in PHC's and purpose of the study was explained and they were asked anonymously to fill the structured questionnaire.

\title{
Inclusion criteria-
}

Those who were present on the day of visit at PHC's

\section{Exclusion criteria-}

Those who were not present on the day of visit at PHC's.

\begin{abstract}
About the questionnaire-
A self-administered questionnaire consisting of both open ended and close ended questions, was used to assess the Knowledge, attitude and practice of medical officers about the dental treatment. Validity and reliability was checked (Cronbach's a $=0.80$ ).

Prior to the study the permission was taken from the block administrator of PHCs . The sampling was done according to the convenience of investigator. A total of 36 doctors were investigated. The questionnaire contained 19 questions about the knowledge, attitude and practice of medical officers of dental treatment. It was in English language. The medical officers were approached personally in the PHC's and the purpose of the study was explained and they were asked to anonymously fill out a structured questionnaireincluded the knowledge, attitude, and practice of medical, dental and hospital setup. It was also mentioned that responses would remain confidential.
\end{abstract}

\section{Results}

A total of 36 doctors of different PHCs of Amer and Jamwaramgarh tehsil, Jaipur were investigated. All these doctors filled the questionnaire provided by the investigator. Amongst the participants 13 were females and 23 were males. The mean age of 34.08 years.The duration of professional life of the medical participants ranged from 1-30 years with mean of 8.39.(Graph 2 )Amongst the medical practitioners 15 had hospital practice while 21 had both clinical and hospital practice.Knowledge, attitude and practice of the participants was compared with their qualification, age, work experience.

Based on their Knowledge about the dental problems the 44.4 percent doctors said patients comes with dental problems at PHCs. 86.11 percent patients at PHCs came with gum problems. 88.8 percent doctors agreed for the training program running for ASHA/Dais workers.94.4\% doctors said that Auxiliaries manage the bifunctional work. 75 percent doctors agreed for the infrastructure present there for emergencies. Only 6 beds were present at 66.6 percent .(Table 1$)$

Based on their attitude , 44.4 percent doctors examine the patients with dental problems. 100 percent doctors told about the importance of oral health. 58.3 percent doctors refer the patient to private hospital.94.4 percent felt the need of dentist, 83.3 percent doctors attended continued medical education program. (Table 2)

Based on their practice, only 25 percent provide the dental treatment, no dental clinic separately found at PHCs. 55.5 percent doctors prescribed both (antibiotic \& pain killer). 94.4 percent provide dental service, 83.3percent doctors said that preventive program being ran by them.75 percent doctors provide only vaccination, 55.5 percent said ambulance is having all basic life supports. 58.3 percent said all equipments are in good condition in ambulance. 100 percent doctors said that vaccination program are running by them at community level. ( Table 3)

Doctors having masters degree did not found difficulty to diagnose patients with dental ailments when compared with graduates it showed statistical significance.(Graph1)On comparing the qualification with the treatments given to the patients withdental problems other than medication there was no statistically significant difference found among the masters and MBBS.Out of 36 participants 34 feel for need of dentist in PHC and in which 23 males and 11 were females and it had showed significant difference when compared with gender.(Graph 3). 
Table no 1 :Responses of study subjects based on their knowledge

\begin{tabular}{|c|c|c|c|c|c|}
\hline Questions on knowledge & Response & Total-36 & Masters-27 & MBBS-9 & \\
\hline \multirow{2}{*}{$\begin{array}{l}\text { Do patients with dental } \\
\text { problems come to PHC? }\end{array}$} & a) Yes & 16 & 16 & 00 & $9.6 \mathrm{p}=0.008, \mathrm{~S}$ \\
\hline & b) No & 20 & 11 & 9 & \\
\hline \multirow{4}{*}{$\begin{array}{l}\text { What are the common } \\
\text { dental problems you come } \\
\text { across? }\end{array}$} & a)Dental caries & 5 & 3 & 2 & \multirow{4}{*}{$\begin{array}{l}0.69 \\
\mathrm{p}=0.70, \mathrm{NS}\end{array}$} \\
\hline & b ) Gum problem & 31 & 24 & 7 & \\
\hline & c) Dental fluorosis & 00 & 00 & 00 & \\
\hline & d) any other & & 00 & 00 & \\
\hline \multirow{2}{*}{$\begin{array}{l}\text { Is there any training } \\
\text { program carried out for } \\
\text { Health Guides /ASHA/Dai? }\end{array}$} & a)Yes & 32 & 25 & 7 & $1.50 \mathrm{P}=0.47, \mathrm{NS}$ \\
\hline & b)No & 4 & 2 & 2 & \\
\hline \multirow{2}{*}{$\begin{array}{l}\text { Does auxillaries manage } \\
\text { the bifunctional work that } \\
\text { is medical as well as dental }\end{array}$} & a)Yes & 34 & 27 & 07 & $6.35 \mathrm{P}=0.04, \mathrm{~S}$ \\
\hline & b)No & 2 & 00 & 02 & \\
\hline \multirow{2}{*}{$\begin{array}{l}\text { Does the infrastructure of } \\
\text { PHC is sufficient for } \\
\text { emergency cases? }\end{array}$} & a)Yes & 27 & 21 & 6 & $0.44 \mathrm{P}=0.88, \mathrm{NS}$ \\
\hline & b)No & 9 & 6 & 3 & \\
\hline \multirow{3}{*}{$\begin{array}{l}\text { How many beds are } \\
\text { available in PHC's? }\end{array}$} & a) & 24 & 21 & 3 & $7.45 \mathrm{P}=0.11, \mathrm{NS}$ \\
\hline & $>6$ & 1 & 1 & 0 & \\
\hline & $<6$ & 11 & 5 & 6 & \\
\hline
\end{tabular}

Table no.2: Responses of study subjects based on their attitude

\begin{tabular}{|c|c|c|c|c|c|}
\hline Questions on attitude & Response & Total-36 & Masters-27 & MBBS-9 & \\
\hline $\begin{array}{l}\text { Examine patients with } \\
\text { dentalproblems? }\end{array}$ & a)Yes & 16 & 16 & 00 & $9.60 \mathrm{P}=0.008, \mathrm{~S}$ \\
\hline $\begin{array}{l}\text { Importance of maintaining } \\
\text { oral health? }\end{array}$ & a)Yes & 36 & 27 & 9 & NA \\
\hline \multirow{2}{*}{$\begin{array}{llr}\text { Where do } & \text { you } & \text { refer the } \\
\text { patients } & \text { with } & \text { dental } \\
\text { problems? } & & \\
\text { latent }\end{array}$} & a)Private & 21 & 17 & 4 & $0.95 \mathrm{p}=0.62, \mathrm{NS}$ \\
\hline & b) Govt dental hospital & 15 & 10 & 5 & \\
\hline $\begin{array}{l}\text { Do you feel the need of } \\
\text { dental auxiliaries and } \\
\text { dentist in PHC? }\end{array}$ & b)No & 2 & 02 & 00 & \\
\hline \multirow{2}{*}{$\begin{array}{l}\text { Have you attended any } \\
\text { continued } \\
\text { medicaleducational } \\
\text { program? }\end{array}$} & a)Yes & 30 & 23 & 7 & $0.26 \mathrm{P}=0.87, \mathrm{NS}$ \\
\hline & b)No & 6 & 4 & 2 & \\
\hline
\end{tabular}

Table no 3:Responses of study subjects based on their practice

\begin{tabular}{|c|c|c|c|c|c|}
\hline Questions on practice & Response & Total-36 & Masters-27 & MBBS-9 & \\
\hline \multirow{2}{*}{$\begin{array}{l}\text { Do you provide any dental } \\
\text { services? }\end{array}$} & a) $\quad$ Yes & 9 & 9 & 00 & $4.00=0.13, \mathrm{NS}$ \\
\hline & No & 27 & 18 & 9 & \\
\hline \multirow{2}{*}{$\begin{array}{l}\text { At your PHC do you have } \\
\text { separate dental clinic? }\end{array}$} & Yes & 00 & 00 & 00 & \\
\hline & b) $\quad$ No & 36 & 27 & 9 & NA \\
\hline \multirow{3}{*}{$\begin{array}{l}\text { Which medicines are you } \\
\text { prescribing commonly to } \\
\text { dental problems? }\end{array}$} & a)Painkiller & 10 & 00 & 7 & \multirow[t]{3}{*}{$25.13 \mathrm{P}<0.0001, \mathrm{~S}$} \\
\hline & b)Antibiotics & 6 & 7 & 2 & \\
\hline & c)Both & 20 & 20 & & \\
\hline \multirow{2}{*}{$\begin{array}{l}\text { Do you provide any dental } \\
\text { service? }\end{array}$} & Yes & 34 & 27 & 07 & $6.35 \mathrm{P}=0.04, \mathrm{~S}$ \\
\hline & No & 2 & 00 & 02 & \\
\hline \multirow{2}{*}{$\begin{array}{lr}\begin{array}{l}\text { Do you run any } \\
\text { programs }\end{array} & \text { preventive } \\
\text { schoolchildren? } & \text { for } \\
\end{array}$} & Yes & 30 & 24 & 6 & $2.40 \mathrm{p}=0.20, \mathrm{NS}$ \\
\hline & No & 6 & 3 & 3 & \\
\hline \multirow{3}{*}{$\begin{array}{lrr}\text { What facilities } & \text { are } \\
\text { provided here } & \text { for } \\
\text { emergencies? } & \end{array}$} & Delivery & 0 & 0 & 0 & $0.44 \mathrm{P}=0.80, \mathrm{NS}$ \\
\hline & Trauma & 9 & 6 & 3 & \\
\hline & Vaccination & 27 & 21 & 6 & \\
\hline \multirow{2}{*}{$\begin{array}{l}\text { Does ambulance is well } \\
\text { furnished with basic life } \\
\text { savingequipments? }\end{array}$} & Yes & 20 & 15 & 5 & \multirow[t]{2}{*}{$0.000 \mathrm{P}=1.00, \mathrm{NS}$} \\
\hline & No & 16 & 12 & 4 & \\
\hline \multirow{2}{*}{$\begin{array}{l}\text { Are all equipments in } \\
\text { ambulance in good } \\
\text { condition? }\end{array}$} & Yes & 21 & 21 & 0 & $16.80 \mathrm{P}=0.0002, \mathrm{~S}$ \\
\hline & No & 15 & 6 & 9 & \\
\hline \multirow{2}{*}{$\begin{array}{l}\text { Are vaccination program } \\
\text { carried out here at } \\
\text { community level? }\end{array}$} & a)Yes & 36 & 27 & 9 & NA \\
\hline & b) No & 00 & 00 & 0 & \\
\hline
\end{tabular}


Graph 1- Qualification Vs difficulty to diagnose patients with dental ailments

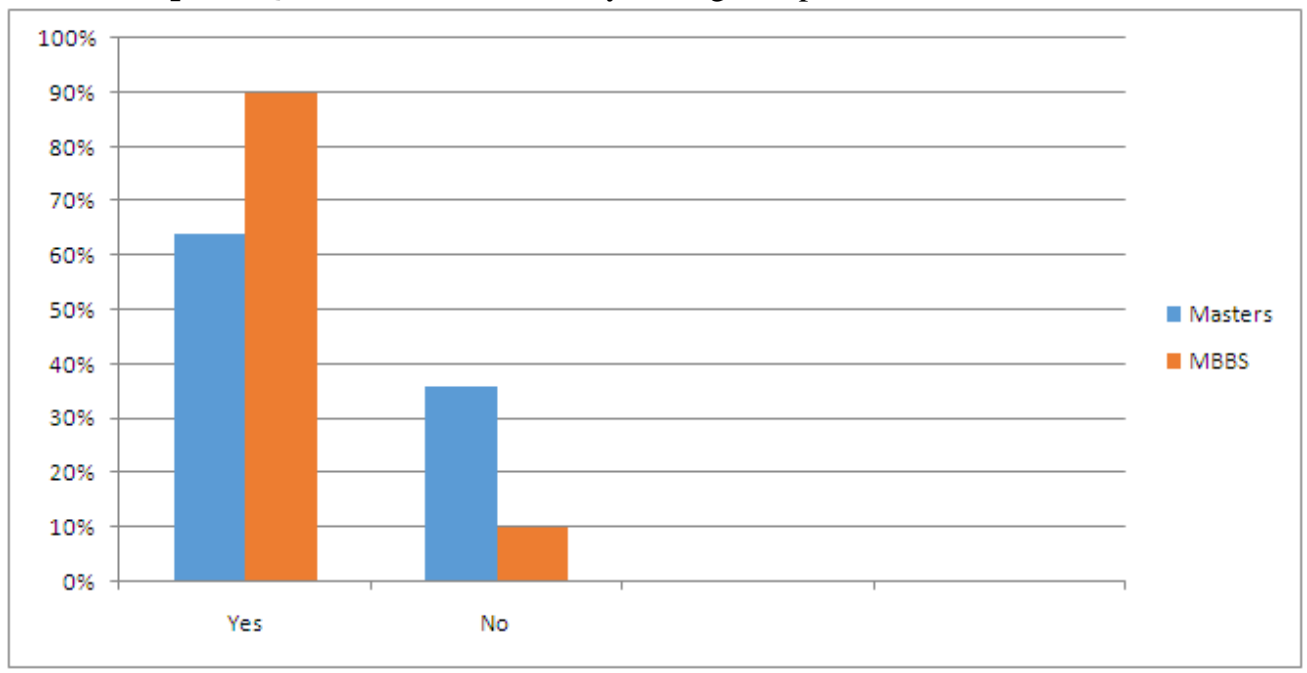

$\aleph 2$-value $=21.49, \mathrm{p}$-value $<0.0001, \mathrm{~S}$

Graph 2 Experience vs. feel for a need of a dentist in PHCs?

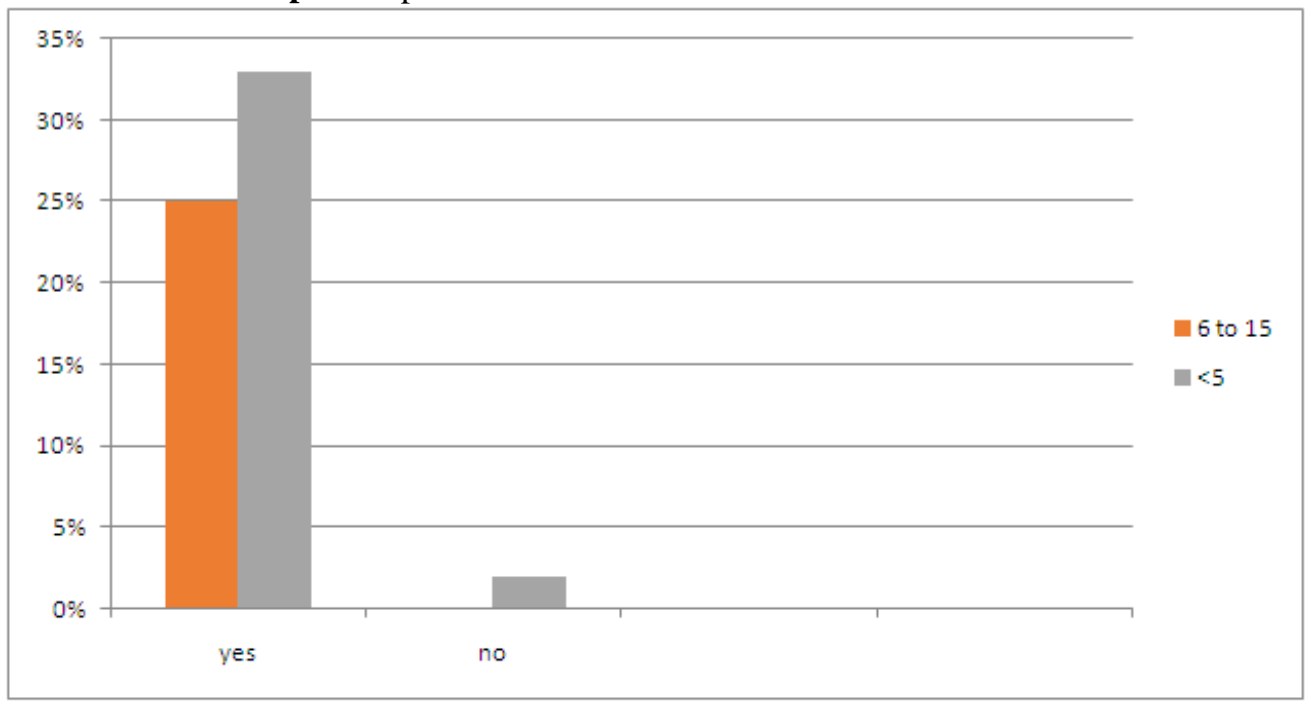

$\aleph 2$-value $=3.38, \mathrm{p}$-value $=0.18, \mathrm{NS}$

Graph 3- Gender Vs feel for a need of a dentist in PHC s? 


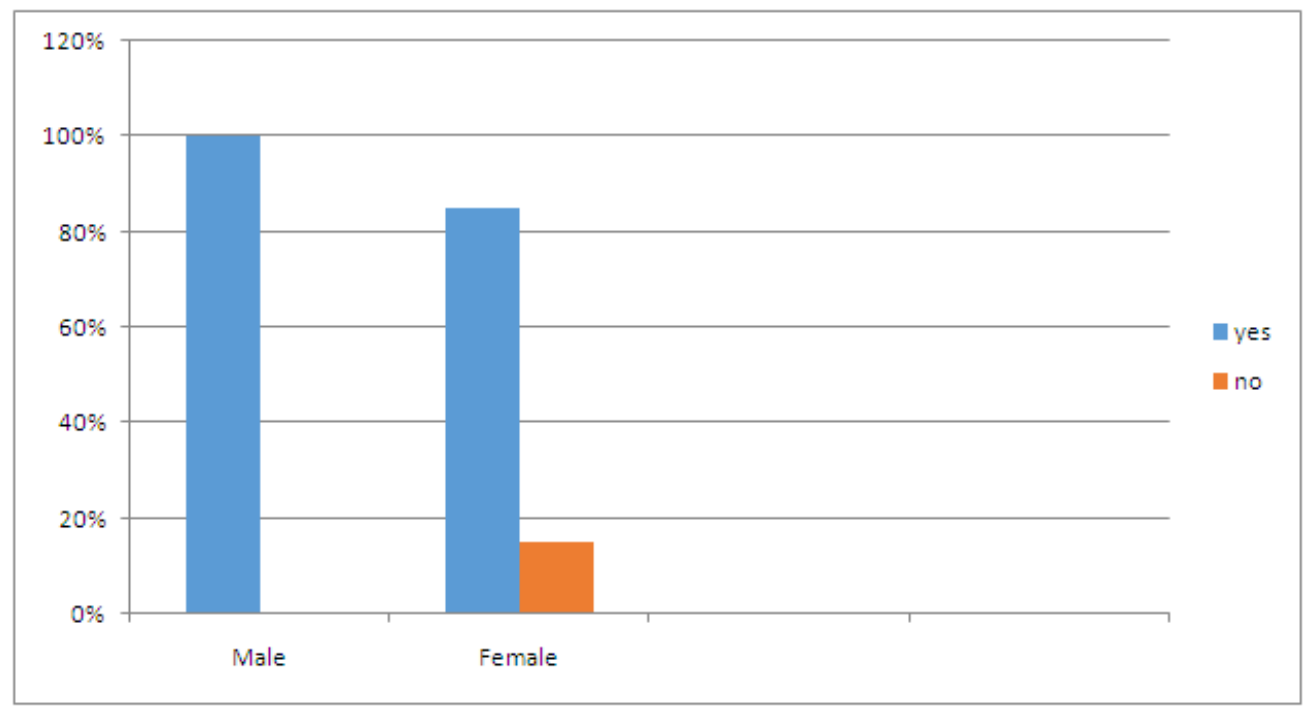

«2-value $=19.78, \mathrm{p}$-value $<0.0001, \mathrm{~S}$

\section{Discussion}

The PHC is considered an opportune site toreach large numbers of patients who make a medicalvisit but not adental visit. Physicians canprovidescreening services for early detection of dentaldisease,provide advice about the need to seek dentalcare, and referthose in need.As William Osler said mouth is the mirror of general health ${ }^{4}$. Poor oral conditionsmay adversely affect general health andcertain medical conditions may have anegative impact on oral health 5 . Thiscross sectional study was conducted toassess the dental knowledge, attitude andawareness of different medical practitioners of Amer and Jamwaramgarh, Jaipur.

In this study, percentage of female medical officers was low compared to Georgia et al's survey $(30.55 \%$ vs 53\%) . All the medical officers felt that referring patients for dental care as part of their regular practice and this percentage was larger than that of Georgia et al's survey $(90 \%)^{2}$. The findings from this study suggest that the majority of medical officers do notwait until the patients have pain or the dental diseases are in advanced stage before they refer. This provides the basis for an encouraging "middle ground" between referring all patients, regardless of their characteristics.

In the present study all the medical officers reportedthat they perform dental examination for all thepatients and this percentage was higher in contrast toa study by Richeal Ni Riordain et al $(63.6 \%)^{5}$.

A recentUSSurgeon General's workshop resulted in astrong recommendation that preventive oral healthcare and risk-based dental referrals be provided inphysicians' offices. Difficulty in making dental referralsreported by medical practitioners in this study, whichlikely reflects actual problems with access to dentalcare for patients, reveals a major barrier to theeffectiveness of interventions designed to increasephysicians' involvement in oral health screening, riskassessment, and referral for follow-up dental care.Such efforts directed toward the medical communitywill be ineffective unless sufficient attention is given todental workforce issues. Successful models that bothdevelop the dental workforce and integrate it withmedical care need to be developed before substantialprogress can be made in resolving problems in accessto dental care.

\section{Recommendations}

- Dentists should be posted in every PHC.

- Also the physician's should be provided with emergency management of dental problems.

\section{Limitations:}

This study can't be generalized

\section{Conclusion}

Medical officers at PHCs showed limited knowledgeregarding dental problems. Oral health is neglected inrural areas so there is need for at least one dentist inthe PHCs to promote the oral health of the people.Medical students should also have mix of dentalclinical experiences so that they can provide somebasic dental treatments without any assistance. ThePHCs should be well equipped to treat the patientswith problems needing emergency dental/medical care.

Medical and dental fraternities should havecoordination and work in collaboration with each otherfor the better delivery of patient care. 


\section{Acknowledgement}

I want to give my sincere thanks to my Beloved Parents, teachers Dr.AnupN. ,Dr.Gautam Biswas, Dr.Shravani G., my friends Dr.HimanshuKumawat, Dr.SwastiTambi and Dr.Prateek Jain. And also to all the medical officers of PHC's who participated in the study.

\section{References}

[1]. Al-Hussaini R, Al-Kandari M, Hamadi T. Dental knowledge, attitudes and behaviour among students at the Kuwait university health sciences centre. Medical Principles and Practice 2003;12:260-65.

[2]. ShakeelAnjum M, Parthasarathi Reddy P, SwathiChowdary K. Role of Medical Officers In Referring the Dental Patients In Primary Health Centers Of Ranga Reddy District, Andhra Pradesh, India. . WebmedCentral DENTISTRY 2012;3(10):WMC003736

[3]. Tuti NMD, Shahida MS, Zamirah ZA. Dental knowledge and self-reported oral care practices among medical, pharmacy and nursing students. Journal SainsKesihatan Malaysia 2009;7(1):13 23.

[4]. Jagadish Chandra, Chandu GN, Prashant GM, et al. Dental awareness and attitudes of medical practitioners of Davangere city. Journal of Indian Association of Public Health Dentistry 2006;8:38-43.

[5]. Sumi Y, Nakamura Y, Nagosa, et al. Attitudes to oral care among caregivers in Japanese nursing homes. Gerodontology 2001;18(1):1-6.

[6]. R Ni Riordain, C McCreary. Oral cancer-Current knowledge, practices and implications for training among an Irish general medical practitioner cohort. Oral Oncology,2009, 45(11): 958-962.

[7]. Radha G, ShaikHyder Ali KH, Pushpanjali K. Knowledge and attitude and practice of oral health among nursing staff and nursing students of Bangalore city. Journal of Indian Association of Public Health Dentistry 2008;(11):17-21. 